\title{
HISTORIA DE AMÉRICA LATINA EN LA POLÍTICA AMBIENTAL MUNDIAL. De Estocolmo 1972 a Río de Janeiro $2012^{1}$
}

\author{
http://dx.doi.org/10.21527/2176-6622.2020.54.6-20
}

Recebido em: 7/9/2020

Aceito em: 19/9/2020

Fernando Estenssoro

Doutorado en Estudios Americanos. Académico del Instituto de Estudios Avanzados (Idea) de la Universidad de Santiago de Chile (USACH). http://lattes.cnpq.br/4558486164091267. https://orcid.org/00016010-7115. fernando.estenssoro@usach.cl

\section{RESUMEN}

Este artículo es un análisis histórico sobre 40 años de participación de América Latina y el Caribe (AMLC) en el debate ambiental mundial, o sea, de todo el debate que se realiza en el marco de la Organización de las Naciones Unidas (ONU) y sus convocatorias a los países del mundo destinadas a superar la crisis ambiental global. Este periodo de tiempo va desde la Conferencia de Naciones Unidas Sobre el Estado del Medio Humano en Estocolmo 1972 hasta la Cumbre de Naciones Unidas sobre el Desarrollo Sostenible en Río de Janeiro 2012. Durante este tiempo se proponen, esquemáticamente, cinco grandes momentos que permiten recoger y plantear cuales fueron las principales ideas de AMLC en el debate ambiental y cómo se generaron y expresaron.

Palabras-clave: América Latina. Crisis ambiental. Historia internacional. Tercer Mundo. Tensión Norte-Sur.

\section{HISTÓRIA DA AMÉRICA LATINA NA POLÍTICA AMBIENTAL GLOBAL DE ESTOCOLMO 1972 AO RIO DE JANEIRO 2012}

\section{RESUMO}

Este artigo é uma análise histórica dos 40 anos de participação da América Latina e do Caribe (AMLC) no debate ambiental global, ou seja, de todo o debate que ocorre no âmbito da Organização das Nações Unidas (ONU) e seus apelos aos países do mundo destinados a superar a crise ambiental global. Esse período vai da Conferência das Nações Unidas sobre o Estado do Ambiente Humano, em Estocolmo, 1972, até a Cúpula das Nações Unidas sobre Desenvolvimento Sustentável, no Rio de Janeiro de 2012. Durante esse período, cinco grandes momentos são esquematicamente propostos que permitem reunir e levantar quais foram as principais ideias da AMLC no debate ambiental e como elas foram geradas e expressas.

Palavras-chave: América Latina. Crise ambiental. História internacional. Terceiro Mundo. Tensão Norte-Sul.

\section{SUMÁRIO}

1 Introducción. 2 La Conferencia de Estocolmo 72: América Latina y la primera confrontación Norte-Sur en el debate ambiental. 3 La consolidación de la perspectiva ambiental de AMLC: Medio Ambiente y Desarrollo y ecodesarrollo. $3.1 \mathrm{El}$ concepto de ecodesarrollo. 4 Del concepto de Desarrollo Sostenible a la Cumbre de Río 92. 4.1 La Cumbre de Río 92. 5 De Río 92 a Río +20: de la ilusión al desengaño. 5.1 Johannesburgo 2002. 5.2 Río +20. 6 La propuesta ecuatoriana de Yasuní ITT en el marco de la lucha contra el cambio climático. 7 Reflexiones finales. 8 Referencias.

\footnotetext{
1 Este artículo es parte del proyecto Fondecyt n. 1190481 - América Latina en la Geopolítica Ambiental Pos-Guerra Fría de los Estados Unidos - Antecedentes Históricos y Proyecciones (1989-2017).
} 


\section{INTRODUCCIÓN}

Desde un punto de vista histórico todo el tema referido a superar la crisis ambiental global, o tema ambiental, se instaló formalmente en la agenda política mundial con la realización de la conferencia de la Organización de las Naciones Unida sobre el Medio Humano en Estocolmo en junio de 1972 (Estocolmo 72). En esa oportunidad los países del mundo se dieron cita en la capital sueca preocupados por el alcance que estaba presentando el deterioro de medio ambiente global que amenazaba con poner en riesgo la propia supervivencia humana sobre el planeta. ${ }^{2}$ Por esta razón, en el documento final de esta Conferencia se llamó a toda la comunidad internacional a unir esfuerzos fin de superar esta grave amenaza y crearon el Programa de Naciones Unidas para el Medio Ambiente (PNUMA) destinado a monitorear y facilitar de manera permanente esta lucha contra la crisis ambiental. Desde esa fecha en adelante, este tema se ha ido convirtiendo en un tópico cada vez más importante en la agenda pública mundial, sin embargo, la solución a la crisis ambiental está muy lejos de alcanzarse. Incluso en algunos aspectos, esta crisis solo tiende a agudizarse como es el caso del cambio climático. Por lo tanto, todo indica que alta tensión política en el debate ambiental internacional seguirá marcando la agenda política mundial durante parte importante del presente siglo.

La principal dificultad para superar la crisis ambiental ha radicado, fundamentalmente, en la existencia de profundas discrepancias para entender su carácter y, por lo tanto, que medidas aplicar para su solución, entre los países capitalistas más ricos, desarrollados e industrializados del mundo, también conocidos como Primer Mundo o Norte, y los países subdesarrollados o en vías de desarrollo, identificados como Tercer Mundo o Sur. ${ }^{3}$

Al respecto, desde los orígenes de este debate en la agenda pública mundial, para el mundo subdesarrollado o Sur, quienes causaron esta crisis, o sea sus principales responsables, fueron los países capitalistas más ricos, industrializados y desarrollado, los cuales al construir la llamada Civilización Industrial, impusieron un modo de producción, una división internacional del trabajo y un estilo de vida altamente consumista, que si bien los llevó la cúspide del poder global simultáneamente generaron la crisis ambiental. Además, establecieron un orden internacional caracterizado por una profunda asimetría de poder y oportunidades de vida, en donde el mundo desarrollado e industrializado es el que se lleva las mejores opciones y, además, dicta las reglas. Por lo tanto, para el mundo subdesarrollado la solución real y definitiva a esta crisis sólo se conseguirá cuando el llamado mundo desarrollado o Norte, asuma su responsabilidad en la generación de este problema, cambie su actitud dominadora, comience a actuar con criterios de justicia redistributiva internacional y pague la deuda social y ecológica que han generado con el resto de la humanidad.

En la construcción de esta perspectiva ambiental del Sur, un papel muy destacado ha desempeñado la América Latina y el Caribe (AMLC). En muchos aspectos, esta región del mundo fue pionera y orientadora para todo el Sur de lo que debía ser una perspectiva ambiental del mundo subdesarrollado en el debate ambiental mundial que se realizaba bajo el alero de la Organización de las Naciones Unidas (ONU), de aquí la importancia de su estudio. En este sentido, la evolución y maduración de la perspectiva ambiental latinoamericana durante los cuarenta años que trascurren entre las cumbres ambientales convocadas por la ONU que van desde Estocolmo en 1972 hasta Río de Janeiro en 2012, se puede esquematizar en cinco grandes momentos: 1) Los

\footnotetext{
En el principal documento base destinado a ser discutido y analizado por esta conferencia, se señalaba: "Se enfrenta una crisis ambiental global que pone en riesgo la vida del ser humano y del planeta [...] Nuestras bruscas y vastas aceleraciones - en el crecimiento demográfico, en el uso de la energía y de nuevos materiales, en la urbanización, en los ideales de consumo y en la contaminación resultante - han colocado al hombre tecnológico en la ruta que puede alterar, en forma peligrosa, y quizá irreversible, los sistemas naturales de su planeta, de los cuales depende su supervivencia biológica [...] En pocas palabras, los dos mundos del hombre - la biósfera de su herencia y la tecnósfera de su creación - se encuentran en desequilibrio y, en verdad, potencialmente, en profundo conflicto. Y el hombre se encuentra en medio" (WARD; DUBOS, 1984, p. 39-49).

3 Para la fecha de Estocolmo 72, los países capitalistas desarrollados se identificaban como Primer Mundo y los subdesarrollados, entre los cuales figuraba América Latina y el Caribe (AMLC), como Tercer Mundo. El Segundo Mundo estaba compuesto por la Unión Soviética y sus aliados comunistas de Europa oriental, que también presentaban un importante nivel de industrialización y en un estándar de vida relativamente alto, pero no llegaban a igualar al nivel de desarrollo y del Primer Mundo. Veinte años después, en 1992 cuando se celebró en Río de Janeiro la Cumbre Mundial de Medio Ambiente y Desarrollo y recién finalizada la guerra fría tras la desaparición de la Unión Soviética (1991), los países más ricos, industrializados y desarrollados del mundo, más los ex -países comunistas de Europa oriental y Rusia, con un alto grado de desarrollo e industrialización, se comenzaron a identificar como Norte global y los países que seguían siendo subdesarrollados o antiguo Tercer Mundo, como Sur global. De aquí entonces que, esquemáticamente, a fin de diferenciar entre un mundo desarrollado e industrializado y un mundo subdesarrollado, se tienda a hablar de diferencias Norte-Sur.
} 
inicios del debate con la Conferencia de Naciones Unidas sobre el Estado del Medio Humano en Estocolmo 1972 (Estocolmo 72); 2) La consolidación del pensamiento de AMLC y el concepto de ecodesarrollo entre 1973 y 1983; 3) desde la acuñación del concepto de Desarrollo Sostenible hasta la Conferencia de Naciones Unidas Sobre el Medio Ambiente y Desarrollo de Río de Janeiro en 1992 (Río 92); 4) desde la Cumbre Río 92 a la Conferencia de las Naciones Unidas sobre el Desarrollo Sostenible en Río de Janeiro 2012 (conocida como Río+20); y 5) la propuesta ecuatoriana Yasuní ITT del año 2007, en el debate sobre el cambio climático.

\section{LA CONFERENCIA DE ESTOCOLMO 72: América Latina y la Primera Confrontación Norte-Sur en el Debate Ambiental}

La idea de realizar una reunión mundial sobre el medio ambiente, la Conferencia de Naciones Unidas sobre el Estado del Medio Humano en Estocolmo 1972 (Estocolmo 72), fue una iniciativa fundamentalmente del Primer Mundo, o sea lo países capitalistas más industrializados y desarrollados. ${ }^{4}$ Como bien señaló Maurice Strong, Secretario General de la Conferencia de Estocolmo 72, fue en "los países industrializados donde la preocupación por la contaminación creó la idea original de la Conferencia de Estocolmo" (citado en ESTENSSORO, 2020, p. 110).

Los países capitalistas altamente desarrollados e industrializados estaban conscientes del daño ambiental que habían causado con su proceso de crecimiento económico, y lo mismo ocurría con los países comunistas europeos que también sufrían los impactos de la contaminación producto de su proceso de industrialización. Fenómenos como la lluvia acida que destruía bosques por emanaciones de azufre y otros gases a la atmosfera, las crisis por el smog, la destrucción de la biodiversidad producto de los pesticidas o el envenenamiento de ríos y lagos por desechos industriales, entre otros aspectos, se venían enfrentando desde los años cincuenta tanto en Europa como en los Estados Unidos. Sin embargo, para su solución en gran medida habría bastado con una cumbre de esos países altamente industrializados y desarrollados ¿por qué entonces la necesidad de hacer una cumbre mundial e incluir a los subdesarrollados en ella? El argumento que se entregó, por parte del mundo capitalista desarrollado o Primer Mundo, para justificar esta convocatoria global era que se trataba de una crisis que no reconocía fronteras ni países y que abarcaba al conjunto del ecosistema planetario, o sea era un "problema de todos". Sin embargo, si bien ese argumento podría ser razonable en algunos aspectos, perfectamente se podría haber comenzado con urgentes y reales acciones de reparación (no solo discursivas) por parte de los principales generadores de esta crisis, o sea los países altamente industrializados. Eran ellos los que venían envenenando el planeta desde la Revolución Industrial en adelante y estaban destruyendo los ecosistemas con su sociedad de alto consumo. ¿Por qué no se actuó así entonces?

Lo cierto es que, para el Primer Mundo, era estratégico involucrar al mundo subdesarrollado en este tema porque para ellos, el verdadero y real problema eran los esfuerzos de crecimiento e industrialización del entonces Tercer Mundo o Sur, que era la mayoría de la humanidad, así como el rápido crecimiento demográfico que mostraban estos países más pobres. El Primer Mundo temía que el crecimiento y desarrollo del Tercer Mundo, junto a su rápido aumento de la población, terminase por agotar los recursos naturales y materias primas que eran fundamentales para el funcionamiento de su complejo tecno-industrial. Además, consideraban que si ellos, los más ricos e industrializados del planeta -que eran menos de un tercio de la humanidad-, con su proceso de crecimiento e industrialización habían generado esta crisis y puesto en riesgo el equilibrio eco sistémico global, la industrialización del Tercer Mundo significaba que la crisis ambiental se trasformaría en el apocalipsis ecológico. Por lo tanto, había que interferir en los planes de desarrollo tercermundistas a fin de que estos obedecieran a las necesidades ecosistémicas que asegurasen el predomino y existencia del Primer Mundo. En este sentido, algunos textos como el primer informe del Club de Roma, Los Limites del Crecimiento, con su propuesta de crecimiento cero, van a sintetizar magistralmente esta perspectiva ambiental primermundista:

\footnotetext{
El Segundo mundo, o sea la URSS y los países comunistas europeos también apoyaron la convocatoria a esta Conferencia, sin embargo, no participaron en el encuentro de Estocolmo-72 (salvo Rumania), producto de un llamado a boicotearlo dado que Estados Unidos y sus aliados impidieron que participara Alemania Oriental, en cambio Alemania Federal si pudo participar (ESTENSSORO, 2020).
} 
Si no se modifican las tendencias actuales en cuanto a crecimiento de la población mundial, industrialización, contaminación, producción alimentaria y agotamiento de los recursos, alcanzaremos el límite de crecimiento de este planeta en el transcurso de los próximos cien años. El resultado más probable será una repentina e incontrolable caída de la población y la capacidad industrial (MEADOWS et al., 1972, p. 23).

Como bien explica Paolo Bifani, en el Primer Mundo de fines de los años 60 e inicios de los 70 del siglo

se explicitaba una violenta crítica del concepto de desarrollo dominante, en el cual prevalecía la idea de crecimiento: para muchos desarrollo era (y aún es) sinónimo de crecimiento económico. El debate se polarizó entre una posición extrema que identificaba crecimiento económico con desarrollo y veía, en el mismo, una de las causas fundamentales de la crisis de aquella época: energética, de alimentos, ambiental. En esa perspectiva, el crecimiento y el desarrollo eran negativos, tenían un carácter cancerígeno y la sobrevivencia de la especie humana y del planeta requería que el crecimiento, tanto poblacional como económico, terminara; el objetivo era el crecimiento cero (1999, p. 105).

Como era de esperar, los países del Tercer Mundo en general y los latinoamericanos en particular, reaccionaron con profunda desconfianza frente a este discurso ambiental primermundista. Sospechaban que con la convocatoria a Estocolmo 72, los países desarrollados estaban orientando los esfuerzos del sistema internacional a la priorización y resolución de aquellos temas que venían afectando la calidad de vida de sus ya opulentas sociedades, dejando de lado los esfuerzos por superar el subdesarrollo de la mayoría de la humanidad. Al respecto, el representante de Brasil ante la ONU, Joao Augusto de Araujo Castro, señaló que, si bien al mundo subdesarrollado le interesaba participar de un debate sobre una política ecológica global, no estaban de acuerdo con el menosprecio que el Primer Mundo presentaba a la relación entre medio ambiente y desarrollo y, además, planteó correctamente que este sería el tema que determinaría el curso futuro del debate ambiental entre países desarrollados y subdesarrollados:

El interés en el campo de la ecología, que está centrado en los países desarrollados, se ha visto recientemente acrecentado debido a la repentina toma de conciencia de un posible desequilibrio entre el hombre y la tierra. Como consecuencia de la explosión demográfica y de la mala utilización de los descubrimientos tecnológicos, dicho desequilibrio potencial podría muy bien traer consigo una crisis ambiental que amenace el futuro del género humano [...] Como podría esperarse, los métodos considerados para solucionar sobre bases mundiales la llamada crisis ambiental se inspiraron en las realidades de una determinada área del mundo: la familia de países desarrollados. Además, el conjunto de soluciones disponibles, principalmente de naturaleza técnica, buscan, en primer lugar, hacer más saludables las consecuencias de la Revolución Industrial sin proporcionar necesariamente un instrumento que facilite una mayor distribución de sus beneficios entre todos los Estados [...] Este nuevo orden internacional y la desigual distribución relativa del poder político de los Estados, basado en el empleo y monopolio de las tecnologías avanzadas, puede muy bien considerarse como uno de los más permanentes efectos de la Revolución Industrial. Desde entonces, como corolario del nuevo orden, los países de avanzada tecnología han venido tratando de mantener en el mundo su posición política y económica, mientras que los países menos afortunados tecnológicamente, han estado tratando de alterar, a través del desarrollo, tal statu quo (DE ARAUJO CASTRO, 1972, p. 237-238).

Por lo tanto, de Araujo Castro dejo claro el componente geopolítico y de dominación que los países capitalistas desarrollados ocultaban bajo todo un discurso crítico al crecimiento y desarrollo, bajo el argumento de que había provocado la crisis ambiental global. Y esta era una opinión altamente compartida por los latinoamericanos como bien se destaca en el análisis realizado por Helio Jaguaribe previo a la Conferencia de Estocolmo 72:

Es particularmente de temer que, confrontados con varias formas de escasez ecológica, los centros imperiales y las naciones y grupos desarrollados reservarán todas o casi todas las facilidades escasas para su propio uso, mientras impondrán al resto del mundo las políticas restrictivas sobre la expansión demográfica, económica y tecnológica requeridas para devolver al mundo el equilibrio ecológico (JAGUARIBE, 1972, p. 122).

Por este motivo los países subdesarrollados planificaron boicotear la Conferencia de Estocolmo 72, lo que obligó a Maurice Strong a realizar una negociación con ellos. Para estos efectos, Strong invitó a una reunión a un selecto grupo de 27 personalidades de renombre mundial, fundamentalmente representantes y ex- 
pertos del Tercer Mundo, a fin de alcanzar un acuerdo que recogiera las preocupaciones referidas a superar el subdesarrollo y unirlas al tema de superar el deterioro ambiental según lo entendían en el Primer Mundo. Esta reunión se realizó en el pueblo suizo de Founex en junio de 1971. De esta negociación, en donde participaron importantes latinoamericanos como Enrique Iglesias, Felipe Herrera y Miguel Ozorio da Almeida, entre otros, salió un documento conocido como Informe Founex, que unió dos ideas que hasta ese momento se presentaban como contradictorias: proteger el medio ambiente y alcanzar el pleno desarrollo:

Puede afirmarse que, en gran medida, el actual interés en las cuestiones relacionadas con el medio ambiente ha tenido su origen en los problemas experimentados por los países industrialmente adelantados. Estos problemas son de por sí, en gran parte, el resultado de un nivel elevado de desarrollo económico (...) Sin embargo, los principales problemas ambientales de los países en desarrollo son básicamente diferentes de los que se perciben en los países industrializados. Son principalmente problemas que tienen su raíz en la pobreza y la propia falta de desarrollo de sus sociedades. En otras palabras, son problemas de pobreza rural y urbana (...) Por estas razones, la preocupación por el medio ambiente no debe debilitar, y no es preciso que lo haga, el compromiso de la comunidad mundial - tanto de los países en desarrollo como de los industrializados- de dedicarse a la tarea principalísima de desarrollar las regiones más atrasadas del mundo. Por el contrario, subraya la necesidad no sólo de comprometerse plenamente a alcanzar las metas y objetivos del segundo decenio para el desarrollo, sino también redefinirlas a fin de atacar la miseria que es el aspecto más importante de los problemas que afligen al medio ambiente de la mayoría de la humanidad (INFORME DE FOUNEX-1971, 1983).

El Informe de Founex fue incorporado como parte del documento de discusión de la Conferencia de Estocolmo 72 lo que permitió terminar con la amenaza de boicot, sin embargo la desconfianza de AMLC frente a las verdaderas intenciones que ocultaban los representantes del Primer Mundo detrás de todo su discurso ambientalista no desapareció, como quedó reflejado en el balance de Estocolmo 72 que realizo el representante de Brasil en dicha conferencia, el embajador Miguel Ozorio de Almeida:

En la Conferencia de Estocolmo, los países desarrollados adoptaron una actitud en virtud de la cual se atribuyen, gracias a su desarrollo, un derecho especial a salvarse y perpetuarse, trasladando a los pueblos subdesarrollados, cuya población es más numerosa, la responsabilidad de dejar el espacio necesario en la tierra. Esta actitud es tanto más peligrosa cuanto que tal principio no se discutió públicamente, sino que estaba implícita en los documentos (OZORIO DE ALMEIDA, 1973, p. 28).

Y la historia iba a demostrar que los brasileros tenían toda razón en sus aprensiones y advertencias sobre el enorme contenido geopolítico y de dominación global que se ocultaba bajo el discurso ambientalista y ecologista del Primer Mundo con su particular perspectiva para entender la crisis ambiental global.

\section{LA CONSOLIDACIÓN DE LA PERSPECTIVA AMBIENTAL DE AMLC: Medio Ambiente y Desarrollo y Ecodesarrollo}

Como se desprende de lo anterior, desde Estocolmo 72, para los países subdesarrollados los temas de medio ambiente y desarrollo estaban absolutamente conectados y debían entenderse como un solo proceso. En este sentido, el primer documento donde los latinoamericanos comienzan a fijar su perspectiva para afrontar la Conferencia de Estocolmo 72, surgió de un seminario organizado en 1971 por la Cepal junto al Instituto Latinoamericano y del Caribe de Planificación Económica y Social (Ilpes), titulado Seminario Regional Latinoamericano sobre los Problemas del Medio Ambiente Humano, y que es considerado como una de las primeras aproximaciones de la Cepal al tema ambiental (TAVARES, 2011, p. 70). En este seminario se presentó para la discusión un estudio titulado "El medio ambiente humano y el desarrollo económico en América Latina", donde, al igual que en el Informe Founex, se señaló que la crisis ambiental la habían generado los países desarrollados y si bien podía ser un fenómeno de alcance mundial, el problema era que los países ricos e industrializados solo enfatizaban aquellos aspectos que se derivaban de su propia industrialización y opulencia. Sin embargo, en América Latina y el Caribe (AMLC), ocurría lo contrario, dado que la crisis ambiental se debía a su característica de ser una región subdesarrollada, además de ser una zona biogeográficamente diferente del Primer Mundo, por lo cual debía trazar una solución al tema desde su propia perspectiva en donde las necesidades de superar el subdesarrollo de la región eran determinantes (CEPAL, 1971). 
Otro temprano e importante documento donde se fijó la posición de AMLC en el debate ambiental fue ¿Catástrofe o Nueva Sociedad? Modelo Mundial Latinoamericano, desarrollado por especialistas vinculados a los temas del desarrollo y a las relaciones internacionales, apoyados por la Fundación Bariloche (por lo que también se lo conoce como el informe del Grupo Bariloche), y que busca ser una contrapropuesta al informe del Club de Roma, Los Limites del Crecimiento. Los latinoamericanos comenzaron a trabajar en este documento en 1971 y lo terminaron para 1975. En este informe señalaron que los problemas ambientales no obedecían a los límites físicos de la tierra y a la escasez de recursos naturales frente al acelerado crecimiento de la población mundial, así como los intentos del Tercer Mundo por industrializarse, como proponían los representantes del Primer Mundo. Para el grupo Bariloche existían suficientes recursos y tecnologías para que toda la humanidad pudiera tener una vida digna y ecológicamente sustentable. El problema era la errónea organización de la producción y la desigual distribución de los recursos. O sea, proponían que la crisis ambiental era un problema esencialmente político y no físico. Obviamente, reconocían que este problema político originaba problemas físicos como la contaminación, la perdida de la biodiversidad, la destrucción de ecosistemas y otros, pero la solución definitiva no radicaba en cuestiones técnicas, sino que en soluciones políticas. Y la principal solución política a esta crisis era terminar con la desigual distribución del poder y la riqueza en el mundo (HERRERA et al., 1976).

También cabe mencionar que terminada la Conferencia de Estocolmo 72, se creó una unidad conjunta Cepal-PNUMA (marzo de 1973) encargada de continuar trabajando con esta perspectiva de unir el tema del cuidado del medio ambiente junto a las necesidades de desarrollo en AMLC. Así, entre el 21 de octubre y el 29 de noviembre de 1974 se realizó en Buenos Aires el Primer Curso de Planificación del Desarrollo y Medio Ambiente de América Latina. Igualmente, entre otras acciones que implemento la Cepal, cabe destacar el seminario interdisciplinario "Estilos de desarrollo y medio ambiente en la América Latina", llevado a cabo entre el 19 y 23 de noviembre de 1979 en Santiago de Chile y que reunió a más de quinientos profesionales y personalidades de AMLC. Las ponencias y debates de este evento fueron publicados en 1981, constituyéndose, según Enrique Leff, en una obra "pionera en la reflexión sobre la dependencia y nuevos estilos de desarrollo desde la perspectiva ambiental" (citado en ESTENSSORO, 2020, p. 141).

\subsection{El Concepto de Ecodesarrollo}

De igual forma, a fin de conciliar el tema del cuidado del medio ambiente con las necesidades de desarrollo en AMLC, en la región se trabajó en profundidad el concepto de ecodesarrollo.

Este concepto fue desarrollado por el economista polaco, naturalizado francés y posteriormente brasileño, Ignacy Sachs. Sachs, propuso el concepto de ecodesarrollo en directa crítica a las posturas dominantes que existían en el debate ambiental del Primer Mundo al momento de relacionar los temas del desarrollo y de la crisis ambiental global. La discusión primermundista variaba desde un polo neomalthusiano y apocalíptico, que postulaba una crítica radical a la industrialización y al desarrollo técnico especialmente en el Tercer Mundo y que alimentaba ideologías claramente anti-humanistas, hasta otro polo representado por quienes proponían depositar la solución de la crisis ambiental en manos de las empresas multinacionales y del mercado. En directa confrontación con ambas posturas, Sachs planteó la necesidad de reorientar el concepto de desarrollo dentro de una perspectiva humanista y ecológica, o sea consciente de su interdependencia con la naturaleza, lo que significaba que no se debía imponer mecánicamente el estilo de desarrollo del Primer Mundo en otras realidades geográficas, sociales, culturales y ecosistémicas diferentes como las que existían en el Tercer Mundo.

El ecodesarrollo es un estilo de desarrollo que busca con insistencia en cada ecorregión soluciones específicas a los problemas particulares, habida cuenta de los datos ecológicos, pero también culturales, así como de las necesidades inmediatas, pero también de las de largo plazo (SACHS, 1974, p. 363).

Esto también significaba para Sachs colocar el avance científico-técnico al servicio de la protección de los ecosistemas, o ecotécnica, en directa contraposición con las lógicas de acumulación capitalista que hegemonizaban el concepto de desarrollo y que alienaban al ser humano, destruían la naturaleza y envenenaban el ambiente (1974, p. 364). 
Este concepto, lo hicieron inmediatamente suyo figuras destacadas del debate ambiental latinoamericano de los años setenta e inicios de los ochenta. Como bien planteó Enrique Leff, "las primeras propuestas sobre el ecodesarrollo encontraron en América Latina un territorio propicio para su promoción", de hecho, "el propio Ignacy Sachs consideraba a América Latina la región potencialmente más fértil para acoger sus propuestas y durante los años 70 viajó a varios países - principalmente a México y a Brasil, país en el que tenía vínculos de segunda ciudadanía- para promover el ecodesarrollo" (LEFF, 2009, p. 221-222). Por ejemplo, profesionales vinculados a la Oficina Regional del PNUMA para América Latina el Caribe (ORPALC), así como a la Cepal, publicaron en 1978:

Consideramos al ecodesarrollo como una modalidad del desarrollo económico que postula la utilización de los recursos para la satisfacción de las necesidades de las actuales y futuras generaciones de la población, mediante la maximización de la eficiencia funcional de los ecosistemas a largo plazo, empleando una tecnología adecuada a este fin y la plena utilización de las potencialidades humanas, dentro de un esquema institucional que permita la participación de la población en las decisiones fundamentales (SÁNCHEZ; SEJENOVICH, 1987, p. 154).

En síntesis, el ecodesarrollo fue un concepto de vanguardia en AMLC cuando el debate político ambiental estaba en sus inicios, que unía las ideas de medio ambiente y desarrollo, defendía la existencia de diferentes estilos de desarrollo, adecuados tanto a las características ecológicas como culturales e históricas de cada región y que, además, refutaba las tesis del Primer Mundo que hacían recaer las causas de la crisis ambiental en el crecimiento demográfico del Tercer Mundo y sus intentos de industrialización destinados a superar las condiciones de miseria, sub desarrollo, así como su voluntad de terminar con las históricas condiciones de sometimiento y relaciones sub-alternas respecto de los centros hegemónicos mundiales.

\section{DEL CONCEPTO DE DESARROLLO SOSTENIBLE A LA CUMBRE DE RÍO 92}

Sin embargo, pese al esfuerzo desplegado por los latinoamericanos, el ecodesarrollo no fue el concepto que predomino en el debate internacional al momento de definir la unidad entre medio ambiente y desarrollo, siendo desplazado por el concepto de desarrollo sostenible.

Al respecto cabe recordar que tras la realización de Estocolmo 72 , se acordó que la humanidad se daría cita cada 10 años a fin de estudiar y evaluar los avances sostenidos contra la crisis ambiental y definir nuevas tareas. En este sentido una segunda gran cumbre ambiental se debía llevar a cabo en Nairobi en 1982 (Nairobi 82). Sin embargo, esta iniciativa fracaso totalmente y resultó en una reunión administrativa menor. El fracaso se debió a la conjugación de dos factores principales. Por una parte, la profundización de las diferencias entre el mundo desarrollado y el mundo subdesarrollado respecto a cómo entender el concepto de crisis ambiental global, y por tanto donde poner el énfasis en las políticas destinadas a superarlo. Y, por otra parte, el clima internacional entre el bloque comunista y el bloque capitalista había empeorado, tras la llegada de Ronald Reagan y Margaret Thatcher a los gobiernos de Estados Unidos y Gran Bretaña respectivamente.

Tras el fracaso de la reunión de Nairobi 82, al año siguiente, en 1983, la ONU decidió crear la Comisión Mundial de Medio Ambiente y Desarrollo (CMMAD), destinada a reponer el tema ambiental en la agenda de las prioridades políticas mundiales y para lo cual era fundamental buscar una fórmula de consenso entre las perspectivas contrapuestas manifestadas desde Estocolmo 72. Se nombró presidenta de esta Comisión a la noruega Gro Harlem Brundtland, razón por lo que se la conoció como Comisión Brundtland. Esta comisión sesionó durante 4 años buscando una fórmula de consenso, en donde la propuesta latinoamericana de utilizar el concepto de ecodesarrollo fue derrotada y en su lugar se implementó el concepto de sustainable development, que se tradujo al castellano indistintamente como desarrollo sostenible o sustentable, y que fue ampliamente explicado en su conocido informe de 1987 Nuestro Futuro Común (ESTENSSORO, 2020). ${ }^{5}$

\footnotetext{
"El desarrollo sostenible es el desarrollo que satisface las necesidades de la generación presente sin comprometer la capacidad de las generaciones futuras para satisfacer sus propias necesidades. Encierra en sí dos conceptos fundamentales: el concepto de "necesidades", en particular las necesidades esenciales de los pobres, a las que se debería otorgar prioridad, [y] la idea de limitaciones impuestas por el estado de la tecnología y la organización social entre la capacidad del medio ambiente para satisfacer las necesidades presentes y futuras [...] como exigencia mínima, el desarrollo duradero no debe poner en peligro los sistemas naturales que sostienen la vida en la Tierra: la atmósfera, las aguas, los suelos y los seres vivientes" (CMMAD, 1992, p. 29, 76).
} 
Ese mismo año de 1987, la Asamblea General de la ONU, felicitó el trabajo de la CMMAD y aceptó el concepto de desarrollo sostenible según lo habían definido y en 1989, sobre la base de este concepto, convocó a una nueva gran cumbre sobre el medio ambiente, a celebrarse en 1992 en la ciudad de Río de Janeiro, pero esta vez titulada como Conferencia de Naciones Unidas Sobre el Medio Ambiente y Desarrollo (Río 92), también conocida como Cumbre de la Tierra, y destinada a relanzar el tema ambiental como uno de los más importantes de la agenda política mundial.

\subsection{La Cumbre de Río 92}

El informe Bruntland no sólo permitió realizar a una nueva gran Cumbre Ambiental veinte años después de Estocolmo 72, sino que también permitió retomar la idea que cada 10 años la comunidad internacional realizará una gran Cumbre para evaluar el estado de avance de la lucha contra la crisis ambiental global. En este sentido, tras la publicación de Nuestro Futuro Común se han realizado 3 grandes cumbres ambientales: Río 92, Johannesburgo 2002 y Río-2012 o Rio +20. Y la próxima debería realizarse en el año 2022.

Respecto de Río 92, sin duda que el ánimo general con que los países de AMLC llegaron a esta conferencia fue muy distinto al de Estocolmo 72. Durante el lapso de 20 años transcurridos entre ambas conferencias, los latinoamericanos se habían destacado por perseverar en la idea de que desarrollo y medio ambiente eran un solo problema y que, mientras existieran más de dos tercios del mundo sumidos en el subdesarrollo, no había posibilidades de solucionar la crisis ambiental. En este sentido, para el Sur en general y los latinoamericanos en particular, la dimensión social del tema ambiental era absolutamente prioritaria y urgente. Por cierto, los latinoamericanos no desconocían que se trataba de un problema global y que ellos también debían realizar su aporte para su superación, pero insistían claramente que no todos tenían la misma responsabilidad en la generación de esta crisis ambiental. En este sentido, los países del Sur en general y de AMLC en particular serán fuertes defensores del principio de Responsabilidades Comunes Pero Diferenciadas (CBDR, según sus siglas en inglés) ${ }^{6} y$, bajo este principio, señalaran que los países más desarrollados, ricos e industrializados del planeta debían hacerse cargo de la deuda ecológica que habían contraído con los países menos desarrollados, lo que se expresará tanto en demandas de apoyos económicos y sociales, y transferencias tecnológicas desde el Norte al Sur, así como la condonación de la deuda externa de los países sub desarrollados, entre otras medidas tendientes a facilitar la superación de los enormes problemas sociales del Sur.

Los latinoamericanos expresaron estos planteamientos en un documento que elaboraron como pre-informe de convocatoria para Río 92, titulado Nuestra Propia Agenda, en donde señalaron que si bien era necesario avanzar en un plan mundial común y coordinado para superar la crisis ambiental, este debía atender a las características específicas de cada región y no pretender un plan con medidas únicas y uniformes para todo el mundo dictadas por las perspectivas ambientales del Norte, debido a que esta crisis ambiental no actuaba de manera uniforme y tampoco afectaba de la misma manera a ricos y pobres:

Las amenazas de la actual crisis económica y ambiental están arraigadas en modalidades de desarrollo imperfectas: la economía de la opulencia y el despilfarro en el Norte y la economía de la pobreza, la desigualdad y necesidades apremiantes de supervivencia a corto plazo en el Sur (citado en ESTENSSORO, 2020, p. 171).

En este documento los latinoamericanos delinearon tres grandes puntos que consideraban fundamentales de resolver en la cumbre de Río 92: en primer lugar, las estrategias regionales de tratamiento de la crisis ambiental, aspecto enfatizado por América Latina y el Caribe; en segundo lugar, temas que afectaban al ecosistema mundial, como el calentamiento global -que enfatizaban los países del Primer Mundo pero sobre el cual la responsabilidad de la región era muy menor-; y por último, temas de política mundial, como la deuda ecológica que el Norte tenía con el Sur, así como el tema de la enorme deuda externa que mantenían los países subdesarrollados producto de un sistema económico financiero controlado por el Norte (ESTENSSORO, 2020).

\footnotetext{
Este principio busca que las obligaciones y contribuciones comprometidas por los Estados frente a determinados problemas comunes estén en directa relación a sus capacidades económicas, técnicas y grados de desarrollo, así como a sus propias necesidades de desarrollo. En este sentido, se trata de una discusión que tiene larga data en los debates internacionales y que busca que los países menos desarrollados tengan un nivel distinto de obligación con relación a los países altamente desarrollados o Norte, así como ser beneficiados con medidas de apoyo por parte del Norte para alcanzar el desarrollo (CERDA, 2016; ARÍ́STEGUI, 2012).
} 
En varios aspectos la cumbre ambiental de Río 92 fue bastante exitosa. Entre sus resultados están los documentos que iban a orientar la discusión ambiental en los años siguientes: la Convención Marco sobre Cambio Climático; la Convención sobre Diversidad Biológica; la Declaración de Principios sobre el Manejo, Conservación y Desarrollo Sustentable de Todos los Tipos de Bosques; la Declaración de Río sobre Medio Ambiente y Desarrollo y, finalmente, la Agenda 21.

Sin embargo, no todas las esperanzas y expectativas que los latinoamericanos y el resto de los países del Sur depositaron en esta cumbre se cumplieron. La demanda relativa a que el Norte reconociera y asumiera el problema de la deuda ecológica, no se consiguió, así como tampoco el tema de subsanar la deuda externa del mundo subdesarrollado. Los representantes del Norte, "propusieron un programa con temas estrictamente ambientales y se mostraron reacios a incorporar los temas del desarrollo en el análisis de los problemas ambientales", y solo priorizaron aquellos temas que consideraban globales tales como el "Cambio Climático, diversidad biológica, océanos y la capa de ozono" (GLENDER, 1994, p. 269). Igualmente, en la discusión que llevó a la firma de la Convención Sobre la Diversidad Biológica, el Norte se preocupó de evitar que se "establecieran obligaciones jurídicamente vinculantes relativas a la transferencia de tecnología, así como la distribución de los beneficios biotecnológicos a los países del Sur" (FUENTES, 2003, p. 36). Pese a esto, se ha señalado que su gran mérito fue "que sentó las bases para la evolución posterior de un derecho internacional del desarrollo sustentable" (p. 37).

\section{DE RÍO 92 A RÍO +20: DE LA ILUSIÓN AL DESENGAÑO}

Si bien se puede considerar a la cumbre de Río 92 como relativamente exitosa, en ningún caso la tensión en el debate ambiental entre el mundo desarrollado y el mundo subdesarrollado, nacida en Estocolmo 72, desapareció. Por el contrario, esta tensión solo mostró una evolución producto de las nuevas circunstancias históricas que se vivían.

Al respecto, se debe recordar que la cumbre de Río 92 se realizó algunos meses después de la desintegración de la Unión Soviética en 1991 que marcó el fin de la Guerra Fría, iniciándose un período de incertidumbre en el orden internacional que sólo se ha acentuado desde entonces. Sin embargo, en un primer momento esta situación no se percibía así. Por el contrario, el bloque capitalista liderado por los Estados Unidos en su calidad de potencia hegemónica indiscutible, estaba exultante y no pocos consideraban que tras la "derrota" del comunismo, la humanidad había entrado en una etapa gloriosa caracterizada por la aceptación mundial, no sólo del liderazgo estadounidense, sino que de toda la cosmovisión occidental propiamente tal, comenzando por su sistema económico, político y cultural. ${ }^{7}$ Pero, por otra parte, debe recordarse que los Estados Unidos, tras la llegada de Ronald Reagan a la presidencia en 1980, había mandado al traste de la basura el modelo capitalista keynesiano y había comenzado a imponer nuevamente un modelo capitalista clásico, popularizado como neoliberal y cuyo recetario será el tristemente célebre "consenso de Washington". En este sentido, la desintegración de la Unión Soviética y el fin de la Guerra Fría, aceleró aún más la imposición a nivel mundial de un capitalismo de libre-mercado o neoliberal, en un proceso que se tenderá a popularizar como globalización, situación repercutirá en el desenvolvimiento del debate ambiental en Río 92, y se acentuará en los años siguientes.

De hecho, en Río 92, el espíritu neoliberal y su propuesta de un capitalismo de mercado verde estaba en pleno desarrollo. De acuerdo con Alberto Glender, los países del Norte, actuando individualmente o representados corporativamente por la Organización para la Cooperación y el Desarrollo Económico (OCDE), "promovieron, como la única forma para solucionar los problemas ambientales, un enfoque de libre mercado y de baja participación de los gobiernos en los asuntos ambientales (...) Asimismo, cuidaron muy bien que el tratamiento de la propiedad intelectual y la difusión de la tecnología se orientara con criterios estrictamente comerciales", además de que "se negaron a tratar los problemas ambientales relacionados con las políticas corporativas o con las empresas transnacionales" (1994, p. 258, 259). Esto significó, entre otros aspectos, que los intereses de los grandes grupos económicos estadounidenses, así como de los países exportadores de petróleo primaran en las negociaciones de la Convención Marco sobre el Cambio Climático (1994, p. 267).

Recuérdese la obra de Francis Fukuyama, El Fin de la Historia y el Ultimo Hombre, que se transformó en un best seller mundial. 
Por lo tanto, bajo una mirada histórica, podemos plantear que en Río 92, o sea veinte años después de Estocolmo 72, el Norte había derivado su inicial discurso eco-catastrofista respecto del desarrollo, sobre todo del Sur, hacia perspectivas más optimistas destinadas a superar la crisis ambiental sin la necesidad de detener el crecimiento económico siempre y cuando el proceso estuviera regido por principios capitalistas de libre mercado. En este sentido, el discurso ambiental hegemónico que se comenzó a imponer desde el Norte tras el fin dela Guerra Fría será el de avanzar hacia un capitalismo "verde", parafraseado como una nueva economía verde. $Y$, en este discurso, el papel de sus empresas trasnacionales pasará a ser determinante, como quedará demostrado en las nuevas cumbres ambientales mundiales que vendrán.

\subsection{Johannesburgo 2002}

Diez años después de Río 92 (y 30 desde Estocolmo 72) se celebró la Cumbre Mundial sobre Desarrollo Sostenible, en Johannesburgo en junio de 2002 (Johannesburgo 2002). El objetivo de esta Cumbre era proponer acciones para acelerar y fortalecer los principios debatidos en Río 92, y como resultados arrojó dos documentos principales: la Declaración de Johannesburgo y el Plan de Implementación. En estos documentos se reafirmó el compromiso con los objetivos de Río 92, y se plantearon metas tales como, reducir a la mitad la proporción de personas sin acceso al agua potable en el mundo para el año 2015 y promover la utilización de energías renovables (VAZ; MACHADO, 2012 , p. 727). Sin embargo, es consensual señalar que fue un encuentro decepcionante por sus resultados, muy por debajo a los arrojados por la cumbre de Río 92. Pero, lo que sí avanzó enormemente en este evento fue la ideología de la globalización neoliberal, promovida por el Norte y el lobby de sus transnacionales.

Como bien se ha señalado, si en 1992 la palabra globalización aún no estaba de moda, esta situación había cambiado totalmente a inicios de los dos mil, y sus promotores entendían que, a fin lograr eficiencia en la consecución de los objetivos del desarrollo sostenible, había que retirar al Estado y sus regulaciones de las soluciones ambientales para imponer las soluciones de libre mercado (FUENTES, 2003). Por estas razones, Nitin Desai, Secretario General de la Cumbre de Johannesburgo 2002 señaló, con cierto tono de preocupación, en su inauguración:

Hoy hablamos cotidianamente y en todas partes de globalización, palabra que en Río apenas si se usaba. Ciertamente, el hecho de que hoy el desarrollo económico está impulsado cada vez por la liberalización del comercio y de las finanzas ha hecho más difícil, en cierto modo, tratar de lograr algunos de los objetivos sociales y ambientales que se fijaron en el gran ciclo de conferencias de las naciones Unidas comenzado con la conferencia de Río (citado en FUENTES, 2003, p. 39).

Por otra parte, los representantes del Norte continuaron con sus políticas evasivas respecto de asumir su responsabilidad en la generación de la crisis ambiental y pagar la deuda ecológica contraída con el conjunto de la humanidad y, sobre todo con los países menos desarrollados. Evitaron cualquier obligación jurídicamente vinculante de ayuda financiera al Sur, salvo en aquellos aspectos de protección al medio ambiente que el Norte consideraba importantes para sus intereses. Esto significó un retroceso en todo lo referido a la ayuda para el desarrollo del Sur, incluso a niveles pre Estocolmo 72. En Estocolmo los países desarrollados se habían comprometido a destinar el $0,7 \%$ de su PIB en ayuda para el desarrollo del Sur. Esta ayuda había disminuido a 0,22\% para la cumbre de Río 92, lo que llevó a que en la Declaración de Río 92 se incluyera el recuperar este compromiso de Estocolmo 72 de comprometer el 0,7\% del PIB del mundo desarrollado para ayudar al Sur. Compromiso que no se cumplió como se comprobó en Johannesburgo diez años más tarde (GUIMARÃES; DA FONTOURA, 2012, p. 24, 25).

Igualmente, los representantes del Norte debilitaron el Principio de las Responsabilidades Comunes pero Diferenciadas, realizando sus más diversas interpretaciones. Así, cuando se discutía el documento de Plan de Acción de esta cumbre los países del Sur, que eran los grandes defensores de este principio y que tenían a Brasil como líder, buscaron avanzar en acciones concretas para su implementación, y si bien lograron que este principio quedara señalado en varias partes del documento, los representantes del mundo desarrollado se encargaron de evitar cualquier tipo de redacción que permitiese una interpretación que llevara a pensar de que el Norte había adquirido "una obligación jurídicamente vinculante de otorgar ayuda financiera a los países pobres" (Ibíd., p. 24). De la misma forma, los países del Norte se encargaron de favorecer los intereses de sus empresas multinacionales influidos por el intenso lobby que éstas desarrollaron. Por ejemplo, el gasto en lobby de 850 mil dólares por parte de la petrolera Exxon, a fin de enviar una carta al entonces Presidente estadounidense George Bush sugiriendo que no fuera a Johannesburgo y boicoteara las negociaciones sobre Cambio Climático (GUIMARÃES; DA FONTOURA, 2012, p. 22). 


\subsection{Río +20}

Diez años después de Johannesburgo 2002 y cuarenta desde Estocolmo 72, se celebró en 2012 la Conferencia de las Naciones Unidas sobre el Desarrollo Sostenible, nuevamente en Río de Janeiro. Dado que ocurría veinte años después de la Cumbre de Río 92, también se la conoció como Río+20. En esta conferencia, no sólo se acentuaron las tendencias registradas en Johannesburgo 2002 relativas al declive de acuerdos consensuados Norte-Sur, sino que en varios aspectos se retrocedió a la realidad pre Río 92 e incluso pre Estocolmo 72.

Por ejemplo, Río+20, a diferencia de Río 92 y Johannesburgo 2002, no fue convocada como una reunión cumbre por parte de la ONU, lo que significaba que la presencia de Jefes de Estado y de Gobierno no era necesaria. De hecho, ni el Presidente de los Estados Unidos, ni la Canciller de Alemania, asistieron al evento, y la Comisión Europea envió una delegación de representante mucho más reducida que para las cumbres anteriores. Nuevamente el Principio de Responsabilidades Comunes pero Diferenciadas (CBDR), fue bastante relativizado y simplificado en su documento final, el Futuro Que Queremos (WENCESLAU; ANTEZANA; CALMON, 2012, p. 597). Al respecto, durante la discusión de este documento, emergieron dos posturas encontradas. Mientras el G- $77^{8}$ y China solicitaban la inserción de la frase "de conformidad con el principio de responsabilidades comunes, pero diferenciadas", los Estados Unidos, con el apoyo de Canadá, Japón y algunos países europeos se opusieron. El G-77 introdujo un texto alternativo señalando "reafirma la Declaración de Río sobre Medio Ambiente y Desarrollo en todos sus principios, en particular el principio de responsabilidades comunes, pero diferenciadas y la equidad". Pero esta vez fue Corea del Sur quien señaló que "el CBDR era un asunto problemático" y agregó que estaba limitado a cuestiones ambientales y que no creía que se pudiera aplicar en temas económicos o de forma general (CERDA, 2016, p. 9). Igualmente, en la redacción de este documento, los países desarrollados se opusieron a planteamientos explícitos del Sur que habían sido ganados en las Cumbres anteriores, tales como "el Derecho al Agua Segura y Limpia y el Saneamiento o la regulación de los mercados financieros y de commodities" (GUIMARÃES; DA FONTOURA, 2012, p. 27).

De la misma forma, y al igual que en las cumbres anteriores, el prometido aumento de la ayuda al desarrollo del Norte para con el Sur, nunca se concretó. El Norte logró que se relativizara cualquier compromiso obligatorio tendiente a pagar su deuda ecológica. Por esto se ha señalado lo que quedó de Río+20 fueron "frases vacías de contenido práctico como las de 'promover la eficiencia' o 'perfeccionar el acceso" (GUIMARÃES; DA FONTOURA, 2012, p. 27).

Lo cierto es que al momento de celebrarse la Conferencia de Río +20 , el mundo estaba bajo la plena hegemonía de un capitalismo neoliberal, en donde las grandes potencias del Norte se habían caracterizado por impulsar políticas y discursos que entregaban la principal, sino toda, la responsabilidad de la lucha contra la crisis ambiental a lógicas del mercado y a los intereses de sus grandes empresas multinacionales. En este sentido, desde Río 92 tanto los Estados Unidos como desde la Unión Europea, principalmente, venían poniendo todos sus esfuerzos y todas sus esperanzas en el gran negocio que resultaría pasar de un capitalismo sucio a un capitalismo verde y de libre mercado, como bien quedará demostrado en el tema de la lucha contra el cambio climático. ${ }^{9}$ En Río +20 , fortalecieron su retórica sobre la necesidad de impulsar una economía verde y un crecimiento verde, en desmedro de los aspectos sociales de la crisis ambiental que es el tema que siempre ha interesado a los latinoamericanos, al punto que en su documento final se aprecia que "los aspectos econó-

\footnotetext{
8 G-77 identifica al grupo de 77 países subdesarrollados y en vías de desarrollo que se agruparon en 1965 a fin de ayudarse mutuamente en las deliberaciones de la ONU. En la actualidad comprende a una mayor cantidad de países pero siguen identificándose como G77.

9 Un claro ejemplo del desarrollo de un mercado capitalista "verde" será la irrupción de los mercados de carbono, tras la firma del protocolo de Kyoto en 1997, destinado a reducir la emisión de gases fecto invernadero (GEI), tales como como el dióxido de carbono (CO ${ }_{2}$ y el metano. El Protocolo de Kyoto estableció un mecanismo que "permite a los países industrializados bajar sus 'cuotas de contaminación' comprando 'aire limpio' a las naciones en vías de desarrollo. Así, aquellas empresas que certifiquen ante una 'autoridad nacional designada" que han bajado sus emisiones de dióxido de carbono, pueden vender estas reducciones (cada certificación equivale a una tonelada de $\mathrm{CO}_{2}$ disminuida) a las compañías del primer mundo que no estén dispuestas a implementar cambios tecnológicos o a bajar sus niveles de producción para contaminar menos. Al fin y al cabo, argumentan los países desarrollados, cuando se restan estas cuotas el beneficio es global, se descontamine el hemisferio Norte o el Sur" (Alonso y Zambra, 2007: 16,17). Igualmente, otro ejemplo de un claro activismo orientado a generar un capitalismo de mercado verde, son los esfuerzos realizados por el ex-vicepresidente de los EE.UU., Al Gore, que tras perder la elección presidencial de 2001 frente a Bush (hijo), comenzó una cruzada personal por pasar del capitalismo "sucio" o centrado en una malla energética fósil a un nuevo capitalismo verde, centrado en una malla energética baja en emisiones de GEl. Sus dos obras principales a este respecto son La Tierra en Juego (1992), y Una Verdad Incómoda (2006).
} 
micos ganaron una fuerza comparativamente superior a los aspectos ambientales en sentido estricto y a los aspectos sociales, como si lo ambiental se subordinara a lo económico" (WENCESLAU; ANTEZANA; CALMON, 2012, p. 597).

En síntesis, en Río+20 siguió manifestándose la tensión ambiental Norte-Sur, e incluso se puede plantear que la situación empeoró notablemente respecto a Río 92. El concepto de desarrollo sostenible quedo muy desdibujado frente al avance del neoliberalismo verde. Al respecto se debe tener presente que este concepto, pese a sus deficiencias, fue el resultado de una larga negociación Norte-Sur al interior de la comisión Brundlandt, y recogió parte importante de la perspectiva ambiental latinoamericana, así como del Sur en general permitiendo que se realizara con éxito la conferencia de Río 92. Sin embargo, 25 años después de su presentación por parte del informe Brundlandt de 1987, había perdido su sentido político de acercar las posiciones Norte-Sur en el debate ambiental, confrontadas desde Estocolmo 72 y pasó a transformarse en un concepto vacío que cada quien interpretará a su arbitrio.

\section{LA PROPUESTA ECUATORIANA DE YASUNÍ ITT EN EL MARCO DE LA LUCHA CONTRA EL CAMBIO CLIMÁTICO}

Un excelente ejemplo concreto para conocer la histórica perspectiva latinoamericana frente al debate ambiental es lo que ocurrió con la iniciativa ecuatoriana Yasuní-ITT, que se hizo en el marco de la lucha contra el Cambio Climático. En este sentido, la propuesta ecuatoriana recogió y expresó el histórico planteamiento de equidad y justicia socio ambiental en el plano de la política mundial que siempre había defendido AMLC, e igualmente su desenlace demostró la permanente política del Norte de bloquear cualquier iniciativa que amenace sus intereses económicos, así como su control y hegemonía de la agenda mundial, en este caso respecto de la temática ambiental.

Al respecto, cabe recordar que el Protocolo de Kyoto, propuesto en 1997, ${ }^{10}$ expiraba en el año 2012 y a medida que esta fecha se acercaba las reuniones anuales de la Conferencia de las Partes de la Convención Marco de las Naciones Unidas sobre el Cambio Climático (COP), se orientaron a lograr un nuevo acuerdo que lo reemplazara y que, esta vez, fuera vinculante para todos los países integrantes de la COP. En este espíritu, según plantea Juan Pablo Vásquez, el año 2007 el Presidente del Ecuador, Rafael Correa, propuso en la Asamblea General de las Naciones Unidas, la Iniciativa Yasuní-ITT que básicamente consistía en mantener bajo tierra, o sea no explotar, más de 840 millones de barriles de petróleo encontrados en el subsuelo amazónico del Parque Nacional Yasuní-ITT y que equivalían al 20\% de la producción petrolera del Ecuador. De esta manera se evitaría la generación de 407 millones de toneladas de $\mathrm{CO}_{2}$ a la atmósfera, además de otros efectos nocivos al ecosistema amazónico como la deforestación, la propagación de metano, la migración de especies y la contaminación de aguas, entre otras (2015a, b). A cambio, Ecuador pedía a la comunidad internacional, una contribución financiera de US\$3.600 millones de dólares según precios internacionales del barril de crudo, equivalente al $50 \%$ de los ingresos que el país dejaría de percibir por no explotar esta fuente de petróleo. Esta cantidad de dinero debía reunirse en 13 años a partir del 2007, siendo un hito condicionante contar con 100 millones de dólares hacia diciembre de 2011 (2015a, b).

Estos fondos serían reunidos en un Fideicomiso Internacional (FI), administrado por el Programa de $\mathrm{Na}$ ciones Unidas para el Desarrollo (PNUD) y gobernado por un Comité de Dirección, en el cual tendrían participación el Gobierno del Ecuador, los contribuyentes y la sociedad civil ecuatoriana. Los dineros del Fondo Yasuní se invertirían en el financiamiento de programas estratégicos de desarrollo sustentable definidos en el Plan Nacional de Desarrollo del Ecuador, todos directamente relacionados a la conservación de la biodiversidad y los ecosistemas, al impulso a las energías renovables, a la investigación, la ciencia, la innovación y tecno-

\footnotetext{
${ }^{10}$ El 11 diciembre de 1997 en la ciudad de Kyoto, se llevó a efecto la COP 3 donde se firmó el conocido Protocolo de Kyoto, inspirado en el principio de Responsabilidades Comunes pero Diferenciadas. En este sentido, el protocolo era vinculante para los 37 países desarrollados y más industrializados del mundo más la Comunidad Europea, los que se obligaban a reducir sus emisiones de GEl en un promedio de $5,2 \%$ respecto a los niveles de 1990, para el período de compromiso comprendido entre el año 2008 y el 2012. En cambio, para los países en desarrollo, así como para China, el protocolo no era vinculante sino solo voluntario. De esta forma, se esperaba que cuando éste caducara en 2012 y se generase un nuevo acuerdo, se habrían alcanzado las condiciones para que fuese vinculante para todos los firmantes (ESTENSSORO, 2019).
} 
logía dirigida al desarrollo de bio-conocimiento y al cambio de la matriz energética. Igualmente, la propuesta señalaba que, si no se reunían los dineros provenientes de la comunidad internacional en los plazos establecidos, se llevarían a cabo los planes extractivos en la zona (2015a, b).

Finalmente, el 15 de agosto de 2013, el gobierno de Rafael Correa dio por terminada la iniciativa señalando su fracaso por la falta de una respuesta adecuada del Norte Global, ya que, tras seis años de esfuerzos sólo se habían reunido 13,3 millones de dólares en el Fondo Yasuní, o sea un 0,37\% de lo esperado, además de otros compromisos no directamente vinculados por otros 116 millones de dólares (ESTENSSORO; VÁSQUEZ, 2017).

Sin embargo, un aspecto crítico para este fracaso fueron las diferencias que ocurrieron relativas a la administración de los fondos a recolectar por parte del denominado Fideicomiso Internacional (FI). Al respecto, en julio de 2008, el gobierno del Ecuador constituyó el Consejo Administrativo y Directivo de la Iniciativa Yasuní-ITT encargado de delinear las políticas para sacar adelante esta iniciativa, trabajar en los mecanismos financieros y desarrollar estrategias de promoción y negociación. Este Consejo estableció negociaciones con el PNUD, para concretar la firma de un $\mathrm{Fl}$, que debía ser presentado para la Cumbre sobre Cambio Climático de Copenhague 2009 sin embargo, las negociaciones fueron suspendidas previo a la celebración de esta Cumbre por el Presidente del Ecuador. Las molestias del Ecuador apuntaban a que el PNUD exigía que el país renunciara a su soberanía al plantear que el FI fuera administrado por una mayoría de miembros representantes de los países contribuyentes (como se había concebido en la propuesta, debían provenir del Norte), lo cual dejaba su administración estratégica - el uso de sus fondos y qué tipos de proyectos llevar adelante con esos mismos fondos -, fuera de la soberanía del sistema público ecuatoriano. Por cierto, esta actitud del Presidente ecuatoriano fue criticada por los gobiernos de los Estados Unidos, Gran Bretaña, Alemania y otros países del Norte, acusándolo de hiper-nacionalista y/o nacionalista económico, así como de no otorgar garantías suficientes a los contribuyentes internacionales. Posteriormente, se tuvo conocimiento por las filtraciones del caso Wikileaks, que los EE.UU. estaban preocupados por lo que denominaban la "obsesión por la soberanía" que presentaba Correa al insistir en la defensa de los recursos naturales del Ecuador, así como las dificultades que ponía el gobierno ecuatoriano para establecer la cooperación militar con los EE.UU., a lo que se sumó la expulsión de dos agentes norteamericanos en febrero de 2009. Por su parte, el gobierno alemán que en sus inicios había manifestado gran apoyo retórico a esta iniciativa del Ecuador, en septiembre de 2010 cambió de actitud y la comenzó a boicotear debido a que el presidente Correa se negaba a dejar el control de la iniciativa en manos internacionales -en donde ellos tenían gran presencia-, y en junio de 2011 Alemania declaró que no seguiría aportando a ésta (ESTENSSORO; VÁSQUEZ, 2017). El Gobierno alemán veía con enorme preocupación la proyección estratégica que significaba la iniciativa ambientalista del Ecuador porque amenazaba con entregar la ofensiva internacional ambiental a los países de la periferia. Concretamente, el Ministro de Cooperación alemán Dirk Niebel en una carta dirigida a la diputada Verde Ute Koczi, informaba que Alemania no aportaría a esta iniciativa, argumentando que no existían garantías por parte del Ecuador de mantener el petróleo bajo tierra, pero además señalaba que "la propuesta ecuatoriana podría formar un precedente peligroso para que otros países productores de petróleo realicen pedidos de compensación similares" (citado en ESTENSSORO; VÁSQUEZ, 2017, p. 74).

En síntesis, se puede señalar que con la iniciativa Yasuní ITT, Ecuador recogía la esencia de los planteamientos históricos de América Latina en el debate ambiental internacional. Como bien señaló Presidente Correa cuando presentó esta propuesta, "no hay peor enemigo para el medio ambiente que la pobreza" (CORREA, 2008, p. A5). Igualmente, la propuesta se inspiraba en el principio altamente valorado por AMLC, como el de las Responsabilidades Comunes pero Diferenciadas y, finalmente, recogía una idea concreta que AMLC venía señalando desde los años 1980, referida a poner valor económico a los múltiples y trascendentales servicios ambientales que prestan los ecosistemas de la región no sólo para el mantenimiento del equilibrio del ecosistema planetario, sino que para el propio mantenimiento del alto estándar de vida de las sociedades del Norte (ESTENSSORO, 2019).

Sin embargo, y pese a las expectativas que originalmente generó esta propuesta, la historia terminó dando a la razón a los peores temores que los latinoamericanos habían manifestado desde un principio en el debate ambienta global respecto de que, más allá de los discursos políticamente correctos y de las declaracio- 
nes de intenciones, el Norte sólo iba a apoyar medidas de mitigación de la crisis ambiental que asegurasen la prevalencia de sus intereses, la continuidad de su hegemonía y el creciente control de ecosistemas mundiales que consideran estratégicos.

En el caso de la propuesta ecuatoriana, el Norte simplemente no podía aceptarla dado que, si ésta tenía éxito, ¿acaso no sería replicada por otros países periféricos que también dependen de la exportación de commodities y recursos naturales hacia los países altamente industrializados? ¿Qué pasaría en el orden internacional económico y geopolítico, si países exportadores de gas, uranio, cobre, litio, u otro recurso natural comenzaran a solicitar a los países del Norte global, que se les pague un precio justo de acuerdo a lo que dejarían de ganar, por no explotar estos recursos, para no provocar daños al medio ambiente? ¿Acaso el sistema industrial y financiero capitalista global no se vería seriamente amenazado, si este tipo de criterio de justicia ambiental se impone? Era evidente para el Norte global que esta iniciativa del Ecuador, que recogió de manera brillante el planteamiento histórico de América Latina, debía obligatoriamente fracasar. Y su resultado, finalmente proyecta que las tensiones Norte-Sur en el debate ambiental no desaparecerán, y AMLC como integrante y defensor de las ideas del Sur global seguirá siendo un protagonista importante.

\section{REFLEXIONES FINALES}

Como se puede apreciar, desde el inicio del debate ambiental en la agenda política mundial, el planteamiento de América Latina y el Caribe ha sido de carácter socioambiental y de defensa de su soberanía. En este sentido, para AMLC la lucha contra la crisis ambiental global siempre ha estado íntimamente relacionada con la lucha contra la pobreza, la desigualdad social y las relaciones desiguales en el comercio internacional. De la misma forma, esta región del mundo ha hecho presente que la crisis ambiental fue generada por los países capitalistas desarrollados. Fueron ellos quienes impusieron un modo de producción y un orden mundial que, junto con otorgarles un elevadísimo estándar y calidad de vida y transformarlos en las potencias hegemónicas del Sistema Internacional, puso en peligro el ecosistema planetario. Esta es la deuda ecológica que el Norte tiene con el Sur y que AMLC ha puesto en el debate ambiental desde un principio. En este sentido, la defensa del principio de Responsabilidades Comunes pero Diferenciadas, así como la ayuda financiera y el traspaso de tecnologías desde el Norte hacia el Sur, son actos y principios que buscan la reparación y el pago de esta deuda ecológica.

Por otra parte, también AMLC ha señalado como el Norte siempre ha estado empeñado en evadir y relativizar todo compromiso tendiente a concretar estas demandas de justicia ambiental internacional. Por ejemplo, no han cumplido con los compromisos tales como aportar con el $0,7 \%$ de su PIB en ayuda al mundo subdesarrollado acordado en Estocolmo 72 e, igualmente han relativizado toda redacción en documentos oficiales que los obligue a medidas similares.

Finalmente, el inteligente boicot que el Norte efectuó a la iniciativa ecuatoriana Yasuní ITT, culpando de su fracaso a los "excesos soberanistas" de Ecuador, fue una de las mayores demostraciones de lo acertadas que fueron las iniciales advertencias realizadas por importantes internacionalistas brasileros, tales como De Araujo Castro, Jaguaribe y Ozorio de Almeida, en los inicios de este debate en Estocolmo 72 y que se puede resumir señalando que ellos advirtieron que la perspectiva ambiental del Norte es geopolítica y de poder. Esto significa que el Norte sólo prioriza medidas que no impliquen debilitar su economía y, sobre todo que no cuestionen o debiliten su poder hegemónico en el orden internacional. Por el contrario, bajo su discurso ambiental, lo que buscan es aumentar su capacidad de injerencia y control de espacios y ecosistemas estratégicos latinoamericanos (entre otros), como fue el caso de la amazonia ecuatoriana.

Estas son algunas de las principales enseñanzas que deja la historia de cuarenta años de participación latinoamericana en el debate ambiental mundial. Debate que se proyecta al futuro con igual o mayor tensión que la manifestada en las décadas analizadas.

\section{REFERENCIAS}

ALONSO, C.; ZAMBRA, D. "El mejor negocio del calentamiento global”. La Nación, Santiago, domingo 13 de mayo de 2007, p. 16-17.

ARÍSTEGUI, J. P. “Evolución del principio 'responsabilidades comunes pero diferenciadas' en el régimen internacional del Cambio Climático". In: Anuario de Derecho Público, Santiago: Universidad Diego Portales (UDP), p. 588-611, 2012. 
BIFANI, P. Medio ambiente y Desarrollo Sostenible. Madrid: Instituto de Estudios Políticos para América Latina, 1999.

CORREA, R. “Ecuador pedirá compensación por no explotar su petróleo". El Mercurio, Santiago, p. A5, 11 de diciembre de 2008. CEPAL. El medio ambiente humano y el desarrollo económico en América Latina. Ciudad de México: Cepal, 1971.

CERDA D. C. "El Principio de Responsabilidades Comunes pero Diferenciadas". Revista Tribuna Internacional, v. 5(10), 2016. Disponible en: https://tribunainternacional.uchile.cl/index.php/RTI/article/view/44493. Acceso en: 5 jul. 2018.

CMMAD. Comisión Mundial del Medio Ambiente y del Desarrollo. Nuestro Futuro Común. Madrid: Alianza, 1992.

DE ARAUJO CASTRO, J. "Environmental and development: The case of the developing countries". In: KAY, D.; SKOLNIKOFF, E. B. (ed.). World Eco-Crisis. International Organizations in Response. Wisconsin: The University Wisconsin Press, 1972. p. $237-252$.

ESTENSSORO, F. Historia del debate ambiental en la política mundial 1945-1992. La perspectiva latinoamericana (Nueva edición corregida y aumentada). Buenos Aires: Biblos, 2020.

ESTENSSORO, F. A geopolítica ambiental global do século XXI. Os desafios para América Latina. Ijuí: Editora Unijuí, 2019.

ESTENSSORO, F.; VÁSQUEZ, J. P. “Las diferencias Norte-Sur en el debate ambiental global. El caso de la propuesta del Ecuador: Yasuní ITT". Universum, v. 32, n. 2, p. 63-80, 2017.

FUENTES T. X. “Los resultados de la Cumbre de Johannesburgo". Estudios Internacionales, v. 36, n. 1, p. 29-53, 2003.

GLENDER, A. "Las relaciones Internacionales del desarrollo sustentable”. In: GLENDER, A.; LICHTINGER, V. (comp.). La Diplomacia Ambiental. México y la Conferencia de Naciones Unidas sobre Medio Ambiente y Desarrollo. México D.F: Fondo de Cultura Económica, 1994. p. 254-282.

GÜIMARÃES, R. "El discreto encanto de la cumbre de la tierra. Evaluación impresionista de Río 92". Nueva Sociedad, n. 122, p. 86-103, 1992.

GUIMARÃES, R.; DA FONTOURA, Y. "Rio+20 ou Rio-20? Crônica de um fracasso anunciado". Ambiente \& Sociedade, v. 15, n. 3, p. 19-39, 2012.

HERRERA, A. et al. Catastrophe or New Society: A Latin American Model. Ottawa: International Development Research Center, 1976.

INFORME DE FOUNEX-1971. In: MARINO DE BOTERO, M.; TOKATLIAN, J. (comp.). Ecodesarrollo. El pensamiento del decenio. Bogotá: Inderena; PNUMA, 1983. p. 51-85.

JAGUARIBE, H. "El equilibrio ecológico mundial y los países subdesarrollados". Estudios Internacionales, año V, n. 17, p. 92-123, 1972.

LEFF, E. “Pensamiento Ambiental Latinoamericano: Patrimonio de un Saber para la sustentabilidad”. In: CONGRESO IBEROAMERICANO DE EDUCACIÓN AMBIENTAL, 6., 2009. Buenos Aires: Secretaría de Ambiente y Desarrollo Sustentable, 2009. p. 215236.

MEADOWS, D. et al. The Limits to Growth. New York: A Potomac Associates Book, 1972.

OZORIO DE ALMEIDA, M. "El Mito del Equilibrio Ecológico". El Correo, XXVI, p. 25-28, 1973.

SACHS, I. "Ambiente y Estilos de Desarrollo". Comercio Exterior, n. 24, p. 360-368, 1974.

SÁNCHEZ, V.; SEJENOVICH, H. "Ecodesarrollo: Una estrategia para el desarrollo social y económico compatible con la conservación ambiental”. Revista Interamericana de Planificación, v. XII, n. 47-48, p. 152-160, 1987.

TAVARES, M. "Economía verde en América Latina: los orígenes del debate en los trabajos de la Cepal". Política Ambiental, n. 8, p. 69-81, jun. 2011.

VÁSQUEZ, J. P. "La tensión histórica norte - sur global en el debate ambiental. El conflicto en torno a la iniciativa Yasuní ITT". Revista Estudios Hemisféricos y Polares, v. 6, n. 1, p. 1-28, 2015a.

VÁSQUEZ, J. P. "Elementos y claves al calor de la conflictividad, para una perspectiva latinoamericana en el debate ambiental: el caso de la iniciativa Yasuní ITT". REDESG, v. 4, n. 2, p. 4-25, 2015b.

VAZ, L. J.; MACHADO, C. R. “Governança ambiental global: atores e cenários”. Cadernos EBAPE.BR, v. 10, n. 3, p. 721-735, 2012. WARD, B.; DUBOS, R. Una Sola Tierra. El cuidado y conservación de un pequeño planeta. México D.F: Fondo de Cultura Económica, 1984.

WENCESLAU, J.; ANTEZANA, N. L; CALMON, P. "Políticas da Terra: existe um novo discurso ambiental pós Rio +20?". Cuadernos EBAPE.Br, v. 10, n. 3, p. 584-604, 2012. 